\title{
A Comparative Study of the Impact of B2B Price Pressure: An Abstract
}

\author{
R. Mohan Pisharodi, John W. Henke Jr., and Ravi Parameswaran
}

\begin{abstract}
Adversarial price reduction pressures are often viewed negatively by suppliers to original equipment manufacturers (OEMs). However, the practice of using price pressure on suppliers is fairly common in numerous industries throughout the world, and literature is unclear on this issue. The current research seeks to challenge the proposition that price pressure on suppliers necessarily results in poor supplier-OEM relationships and to find out whether price reduction tactics and good relationship can exist simultaneously. An eight-construct research model with overall relations as the dependent variable and with price pressure and other OEM subjected pressures (like quality expectations) as the exogenous variables is tested using data collected from North American, European, and Asian suppliers to OEMs who manufacture automobile heavy vehicles and electronic products. Analysis using confirmatory factor analysis and structural equation modeling revealed the existence of similarities and differences between the two data sets. While the automobile data set revealed that the impact of pressure takes place mostly through the relationship variables, the electronics industry data set displayed some direct relationship as well as relationships through the relationship variables. The findings of this research indicate that price pressure and good overall supplier-OEM relationship can coexist if managers take steps to maintain good supplier-OEM relationship.
\end{abstract}

R. Mohan Pisharodi $(\varangle) \bullet$ R. Parameswaran

Oakland University, Rochester, MI, USA

e-mail: pisharod@oakland.edu; paramesw@oakland.edu

J.W. Henke Jr.

Planning Perspectives, Inc., Birmingham, MI, USA

e-mail: henke@ppi1.com 